\title{
Anti-LAG-3 Monoclonal Antibody LAG525
}

National Cancer Institute

\section{Source}

National Cancer Institute. Anti-LAG-3 Monoclonal Antibody LAG525. NCI Thesaurus.

Code $\mathrm{C122683.}$

A humanized monoclonal antibody directed ag ainst the inhibitory receptor lymphocyte activation gene-3 (LAG-3), with potential immunomodulating and antineoplastic activities. Upon administration, the anti-LAG-3 monoclonal antibody LAG525 binds to LAG-3 expressed on tumor-infiltrating lymphocytes (TILs) and blocks its binding with major histocompatibility complex (MHC) class II molecules expressed on tumor cells. This activates antigen-specific T-lymphocytes and enhances cytotoxic T-cell-mediated tumor cell lysis, which leads to a reduction in tumor growth. LAG-3, a member of the immunog lobulin superfamily (IgSF) and expressed on various immune cells, negatively regulates cellular proliferation and activation of T-cells. Its expression on TILs is associated with tumor-mediated immune suppression. 